\title{
Estudo do perfil químico de chás de capim cidreira (Cymbopogon citratus Stapf) mediante a variação na forma de preparo
}

\author{
Study of the chemical profile of lemongrass teas (Cymbopogon citratus Stapf) through variation in \\ the form of preparation \\ Estudio del perfil químico de los tés de limoncillo (Cymbopogon citratus Stapf) mediante variación \\ en la forma de preparación
}

Recebido: 13/08/2021 | Revisado: 22/08/2021 | Aceito: 27/08/2021 | Publicado: 29/08/2021

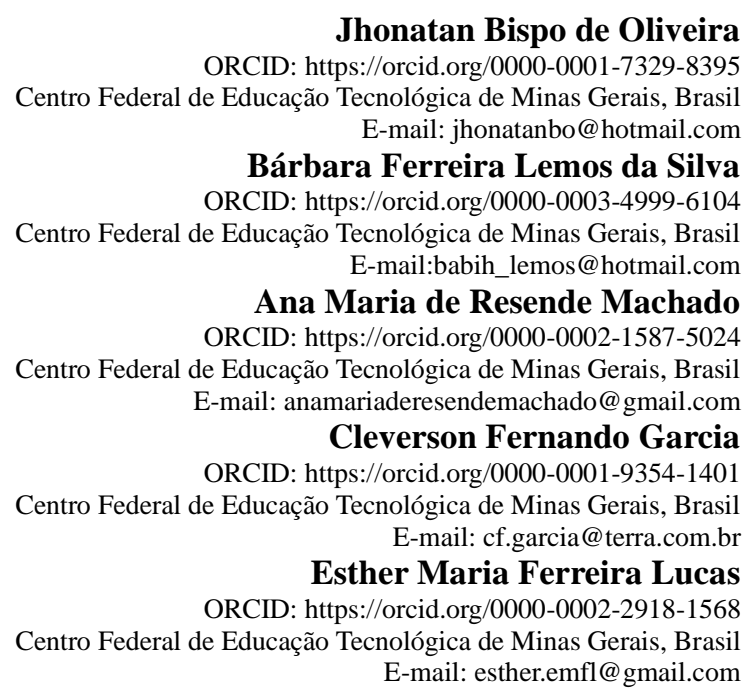

\section{Resumo}

Neste trabalho foi investigado a influência das condições de preparo de "chás" de capim limão, no perfil químico do material extrativo obtido. Para tal, variou-se a forma de armazenamento das folhas e a metodologia empregada durante o processo de extração por infusão e decocção, aplicando planejamento fatorial e análise estatística. Foram construídas duas matrizes de análise relacionando: o emprego de vegetal fresco, seco ou refrigerado com o tipo de extração empregada, nas quais variou-se o tempo de contato entre material vegetal e água fervente. A análise dos extratos envolveu microextração líquido-líquida dispersiva, seguida por cromatografia gasosa acoplada à espectrometria de massas. O processamento dos dados indicou que, não há diferença estatística no uso de folhas secas ou frescas, enquanto emprego de folhas armazenadas, por 7 dias, em refrigerador, conduziu a extratos empobrecidos em fitofármacos. As infusões realizadas sem e com auxílio de ultrassonificação apresentaram capacidade de extração similar. A decoç̧ão conduziu a extratos com presença de metabólitos epoxidados. Quanto maior o tempo de contato entre solvente e material vegetal maiores foram os teores dos compostos bioativos extraídos. Posteriormente, construiu-se uma matriz para estudo univaridado, variando o tempo de extração entre 5 a 65 minutos, com intuito de determinar o ponto máximo de extração. Conclui-se que, a metodologia que garante a extração dos terpenos bioativos em maior proporção e a ausência dos produtos oxidados, no fitoterápico, é a infusão de folhas secas ou frescas do capim limão, onde estas a e água fervente permanecem em contacto por período de 25 minutos.

Palavras-chave: Capim limão; Extração; Fitoterápico; Perfil químico; Cromatografia gasosa; Microextração líquidolíquido dispersiva.

\begin{abstract}
In this work, the influence of the conditions of preparation of lemongrass tea preparation on the chemical profile of the specified herbal medicine was investigated. To this end, the form of storage of the leaves and the methodology used during the process of extraction by infusion and decoction were varied, applying factorial planning and statistical analysis. Two matrices were built, for analysis relating: the use of fresh vegetable, dry or refrigerated with the type of extraction used, in which the contact time between the vegetable material and boiling water was varied. An analysis of the extracts involved dispersive liquid-liquid microextraction, followed by gas chromatography coupled with mass spectrometry. Data processing indicated that there is no difference in the use of dry or fresh leaves, while the use of leaves stored for 7 days in a refrigerator lead to extracts depleted in phytopharmaceuticals. Infusions performed
\end{abstract}


without and with the aid of ultrasonication dissipate similar capacity. The decoction led to extracts with the presence of epoxidized metabolites. The longer the contact time between solvent and plant material, the higher the levels of extracted bioactive compounds. Subsequently, a matrix for univariate study was constructed, varying the extraction time between 5 and 65 minutes, in order to determine the maximum extraction point. It is concluded that the methodology that guarantees the extraction of bioactive terpenes in greater proportion and the absence of oxidized, non-phytotherapic products is the infusion of dry or fresh lemon grass leaves, where these and boiling water remain in contact for a period of 25 minutes.

Keywords: Lemon grass; Extraction; Herbal medicine; Chemical profile; Gas chromatography; Dispersive liquidliquid microextraction.

\section{Resumen}

En este trabajo, se investigó la influencia de las condiciones de preparación de la preparación del té de limoncillo en el perfil químico de la medicina herbal especificada. Para ello se varió la forma de almacenamiento de las hojas y la metodología empleada durante el proceso de extracción por infusión y decocción, aplicando planificación factorial y análisis estadístico. Se construyeron dos matrices, para análisis relacionados: el uso de verdura fresca, seca o refrigerada con el tipo de extracción utilizada, en las que se varió el tiempo de contacto entre la materia vegetal y el agua hirviendo. Un análisis de los extractos involucró microextracción líquido-líquido dispersivo, seguido de cromatografía de gases junto con espectrometría de masas. El procesamiento de datos indicó que no hay diferencia en el uso de hojas secas o frescas, mientras que el uso de hojas almacenadas durante 7 días en un refrigerador condujo a extractos empobrecidos en fitofármacos. Las infusiones realizadas sin y con la ayuda de ultrasonidos disipan una capacidad similar. La decocción dio lugar a extractos con presencia de metabolitos epoxidados. Cuanto mayor sea el tiempo de contacto entre el disolvente y el material vegetal, mayores serán los niveles de compuestos bioactivos extraídos. Posteriormente, se construyó una matriz para estudio univariante, variando el tiempo de extracción entre 5 y 65 minutos, con el fin de determinar el punto máximo de extracción. Se concluye que la metodología que garantiza la extracción de terpenos bioactivos en mayor proporción y la ausencia de productos oxidados no fitoterápicos es la infusión de hojas de limoncillo secas o frescas, donde estas y el agua hirviendo permanecen en contacto por un período de 25 minutos.

Palabras clave: Hierba de limón; Extracción; Medicina herbaria; Perfil químico; Cromatografía de gases; Microextracción líquido-líquido dispersivo.

\section{Introdução}

A fitoterapia é empregada, pelo homem, desde a antiguidade e ainda exibe importância na tradição popular (Stam, 2003; Firmo et al., 2011). Nas políticas públicas de saúde de nosso país é considerada como uma prática complementar de atenção à saúde (ANVISA, 2018). A fitoterapia se fundamenta no emprego de vegetais ou produtos preparados a partir destes, para o tratamento de enfermidades ou seus sintomas. A ação biológica dos vegetais depende da presença dos fitofármacos metabólitos bioativos, que são resultantes do metabolismo secundário das plantas, que não estão diretamente envolvidos nos processos de crescimento, desenvolvimento e reprodução, mas que auxiliam nas interações destas com o ambiente (Firmo et al., 2011).

Atualmente há uma crescente busca de tratamentos com base em produtos e processos naturais, seja pela falta de recurso financeiro de algumas camadas da população, seja pela ação de grupos que seguem ideais de estilo de vida "mais natural", evitando-se ao máximo, a utilização de alimentos processados industrialmente, remédios sintéticos e até vacinas (ANVISA, 2018). Neste contexto, muitas desses grupos buscam, na cultura popular, tratamentos menos agressivos, mais naturais e baratos, como a produção de extratos a partir de plantas, usando os vegetais como recurso disponível para tratamento de enfermidades corriqueiras.

Além de ser uma alternativa para a população, o uso de plantas medicinais também significa valorização das tradições populares e da flora de nosso país, que é muito rica - estima-se que a biota brasileira compreende entre 170 e 210 mil espécies, dentre as quais deve haver aquelas com substâncias ainda não conhecidas e de grande potencial farmacológico (Simões et al., 2017).

A Organização Mundial da Saúde (OMS) estima que 65\% da população mundial utiliza as plantas medicinais e os fitoterápicos para se tratar, porém, as condições de cultivo, armazenamento do material vegetal e metodologias de preparo dos 
fitoterápicos podem conduzir a obtenção de extratos de composições químicas diversas (Singi et al., 2005). Muitas vezes, tais condições podem promover a volatilização, degradação e até a conversão dos metabólitos bioativos em substâncias tóxicas. Sendo assim, os fitoterápicos obtidos podem se tornar ineficazes ou até causar danos à saúde. Neste sentido, fica claro que é de interesse público a intensificação nos estudos que envolvem a química de produtos naturais, farmacobotânica e farmacognosia, no intuito de garantir um uso seguro e eficaz das plantas medicinais e seus fitoterápicos (Simões et al., 2017).

Pertencente da flora brasileira o capim-limão ou capim-cidreira (Cymbopogon citratus Stapf,) é uma planta amplamente utilizada como calmante, antiespasmódico, diurético, contra gripes, dores de cabeça, disenteria e ainda apresenta ações antifúngica e antibacteriana (Shah et al., 2011; Negrelle e Gomes, 2007). A preparação dos fitoterápicos, de capim limão, mais comumente empregados é realizada pelo processo de infusão ou decoç̧ão, originando os chamados "chás" (Singi et al., 2005). Tais chás são preparados a partir das folhas frescas ou secas - a secagem das folhas tem como objetivo a remoção da água para a sua conservação (Martinazzo et al., 2007). As características farmacológicas do capim-cidreira são atribuídas a presença dos terpenos voláteis, como: nerol, geraniol, mirceno, linalol, neral, geranial (Guimarães et al., 2008).

Os óleos essenciais onde o geraniol e o nerol são majoritários, encontram-se misturados com neral e geranial exibiram atividade antifúngica sobre Botrytis cinérea e inseticida sobre Aedes aegypti (Oyedele et al., 2002; Giteru et al., 2015). O nerol isolado, apresentou propriedades: antiprotozoário sobre Leishmania chagasi e Trypanosoma cruzi, neurofarmacológicas, antioxidantes e antivirais sobre o vírus da Herpes (Topal et al., 2008; Escobar et al., 2010; Burke et al., 1997; Friedman et al., 2002). O geraniol isolado apresentou ação antibacteriana sobre H. Influenzae, S. Aureu, E. coli, L. Monocytogenes e $S$. entérica, atividade antioxidante, e ação antineoplásica sobre cultura de células tumorais pancreáticas, atividade acaricida sobre Tyrophagus putrescentiae, além de atividades anti-helmíntica e anti-inflamatórias (Si et al., 2006; Cantrell et al., 2009; Jeon et al., 2009; Chen e Viljoen, 2010). O citral, que corresponde a mistura de dois isômeros, neral e geranial, apresentou ação antiinflamatória, atividade fungicida sobre Cryptococcus neoforman e antibacteriana sobre Campylobacter jejuni, $L$. monocytogenes e Pseudomonas fluorescens, além de ter promovido o fortalecimento imunológico, por estimular as citocinas, (Bachiega e Sforcin, 2011; Marques et al., 2013; Allahverdiyev et al., 2004). O mirceno exerceu efeito analgésico significativo, na administração em camundongos, tendo, sua ação sedativa sido comparável a do fenobarbital com efeito aumentado pela administração simultânea de citral. Este terpeno também mostrou potente atividade anti-inflamatória e anticatabólica (Rao et al., 1990; Gurgel do Vale et al., 2002; Rufino et al., 2015). O linalol exibiu ação anti-inflamatória e analgésica pela inibição da ciclooxigenase-2 (COX-2) (Li et al., 2016), atuou na inibição da proliferação de células de leucemia humana, células do carcinoma do colo do útero e células do adenocarcinoma do pulmão (Maeda et al., 2012; Sobral et al., 2014), também demonstrou atividade antimicrobiana contra S. aureus, E. coli e C. albicans (Herman et al., 2016).

É importante ressaltar que a presença dos metabólitos secundários vegetais em um fitoterápico pode variar conforme as condições de armazenamento do material vegetal e do processo extrativo empregado.

As preparações caseiras com vegetais, como por exemplo da hortelã, partem do material vegetal fresco, seco ou refrigerado. O processo de secagem é vantajoso por propiciar uma maior concentração dos metabólitos, mas o aquecimento pode acarretar volatilização, oxidação, hidrólise e decomposições dos metabólitos. O armazenamento do material vegetal, em refrigerador, tem como objetivo minimizar as perdas dos metabólitos, em temperatura ambiente podem se volatilizar ou que são sensíveis a ação de enzimas vegetais, que sejam ativas nesta temperatura, assim como de minimizar a ação de microrganismos que aceleram o processo de apodrecimento do material pós colheita (Robbers et al., 1996)

A preparação dos "chás" se dá pelos processos de infusão ou decocção. A infusão consiste em deixar em repouso, um sistema no qual tenha sido vertida água fervente sobre o material vegetal, enquanto a decocção consiste em aquecer o sistema formado por material vegetal e água até seu ponto ebulição. Nestes processos, as principais variáveis que podem interferir na composição química do extrato obtido são o fato do o material vegetal ser empregado fragmentado ou inteiro e o tempo de 
contacto entre material vegetal e solvente. A fragmentação do material vegetal pode ser vantajosa por aumentar a superfície de contacto entre droga e solvente, mas pode ser prejudicial, pois ao fragmentar o material, enzimas podem ser liberadas dos interstícios celulares, e acelerar a degradação de metabólitos. Já o aquecimento, pode facilitar a extração, mas também promover perda de metabólitos por volatilização ou degradação (Simões et al., 2017).

Um outro parâmetro que pode atuar na extração dos metabólitos vegetais é o emprego do ultrassom durante o período em que o material vegetal e a água ficam em contato. Este recurso é uma técnica potencial para aumentar as taxas de transferência de massa pela difusão entre as membranas devido ao aumento da penetração do solvente no produto devido ao rompimento das paredes celulares produzidas pela cavitação acústica (Maran et al., 2017). Outra vantagem é que o processo pode ocorrer em temperaturas mais baixas, portanto, mais adequado para aumentar a extração de compostos termicamente instáveis. Deste modo, a ultrassonificação reduz consideravelmente o tempo de extração e pode aumentar o teor de metabólito bioativos no extrato (Falleh et al., 2012).

A decocção e a infusão são métodos que apresentam características que englobam metodologias verdes, por utilizar água como solvente (não tóxico), menor gasto energético e menor tempo do processo, já que a extração se baseia entre tempos que variam de 5 e 25 minutos. O único resíduo gerado que necessita de tratamento é a parte vegetal que poderá ser utilizada em plantações como adubo (Nishiyama et al., 2010; Gnoatto et al., 2007).

Em busca de aperfeiçoar os processos de obtenção de extratos de capim-limão utilizando metodologias que possibilitam a extração dos terpenos voláteis de acordo com os princípios da Química Verde, foi proposto o presente trabalho no qual empregou-se ferramentas estatísticas de estudos fatoriais.

O planejamento fatorial é uma ferramenta que pode ser muito útil quando aplicado ao desenvolvimento de um fitoterápico, pois nestes processos, estão envolvidas diversas variáveis, e a introdução desta ferramenta, torna possível a realização de uma quantidade reduzida de experimentos com economia no tempo, além de conduzir a produtos mais fáceis de serem obtidos. Dentro do planejamento de experimentos, onde há duas ou mais variáveis independentes, é usual o emprego do planejamento fatorial completo, onde é possível medir influências entre as variáveis (fatores). Com intuito de detectar os efeitos entre os fatores é importante fazê-los variar e observar a resposta dessa variação (Cunico et al., 2008).

Esse trabalho teve como objetivo definir as condições de armazenamento do material vegetal e do método de extração, em água, que permitem a obtenção de maiores concentraç̃oes dos metabólitos secundários bioativos nos "chás" de capim limão. Para orientar a definição das variáveis, empregou-se, na metodologia, o planejamento fatorial. Em relação a condição de armazenamento, foram empregadas folhas frescas, secas e armazenadas em refrigerador por período de 7 dias. Em relação às variáveis avaliadas nas condições de preparo foram empregados os métodos de infusão e de decocção, onde o contacto entre material vegetal e água foi mantido por diferentes períodos e, foram preparadas infusões com e sem ultrassonificação, durante o período de contato.

\section{Metodologia}

\subsection{Cultivo e colheita do capim-limão}

O material vegetal (C. citratus) foi cultivado no município de Contagem - MG/Brasil (coordenadas: latitude 19.9694499 e longitude - 44.0628486). A coleta das folhas foi realizada no período da manhã, garantindo-se que o tempo de vida fosse equivalente à seis meses. Foram coletadas folhas jovens, cortadas a uma altura de $30 \mathrm{~cm}$ do solo (Costa et al., 2005). O material vegetal foi armazenado no herbário da Universidade Federal de Minas Gerais (UFMG), sob número de tombamento da amostra vegetal BHCB 205100. 


\subsection{Preparação dos extratos}

Os extratos foram elaborados na proporção de $0,50 \mathrm{~g}$ de material vegetal para $10,0 \mathrm{~mL}$ de água destilada (solvente). Após o período de contato entre material vegetal e solvente, a porção líquida foi separada, utilizando um aparato de filtração simples, com funil de vidro e papel de filtro, resultando em aproximadamente $8,0 \mathrm{~mL}$ de extrato aquoso.

Por sua vez, a otimização do processo de extração dos compostos bioativos de $C$. citratus foi realizada de acordo com o tópico a seguir.

\subsection{Planejamento Fatorial e estudo de modelos de regressão}

Inicialmente, realizou-se dois planejamentos fatoriais completos $2^{3}$, com ensaios em duplicata, sendo o primeiro relacionado aos seguintes fatores e níveis: método de extração (infusão sem ultrassonicação e infusão com ultrassonicação), condição do material vegetal (folhas frescas após a colheita e folhas resfriadas por 7 dias, por aproximadamente $5^{\circ} \mathrm{C}$ ) e período de contato entre o material vegetal e a água (5 e $25 \mathrm{~min}$ ). Por sua vez, o segundo planejamento fatorial levou em conta os seguintes fatores e níveis: método de extração (decocção sem sonicação e decocção com sonicação), condição do material vegetal (folhas frescas após a colheita e folhas desidratadas) e período de contato entre o material vegetal e a água (5 e 25 min). A variável resposta foi composta pela soma das áreas dos picos dos compostos voláteis, obtidas via GC-MS, e cada matriz foi composta por 16 ensaios realizados em ordem aleatória.

Em seguida, com base nos dados quantitativos do período de extração e nas demais variáveis qualitativas otimizadas, aplicou-se um modelo de regressão buscando relacionar o tempo de extração (5, 25, 35, 45 e $65 \mathrm{~min})$ com a soma das áreas dos picos dos compostos voláteis, em duplicata. Para sonicação dos extratos foi utilizado uma lavadora ultrassônica L-220 da Schuster, com capacidade de $1,0 \mathrm{~L}$ e frequência de $20 \mathrm{kHz}$. Todos os dados foram processados com o software Minitab® 19.2020.1 (64-bit).

\subsection{Microextração líquido-líquido dispersiva}

Para possibilitar a análise em CG-MS, os compostos orgânicos dos extratos foram obtidos por meio de microoextração líquida-líquida dispersiva, na qual os extratos oriundos da infusão e da decoç̧ão foram homogeneizados e 700 $\mu \mathrm{L}$ do volume foi transferido para um eppendorf, ao qual foram adicionados $100 \mu \mathrm{L}$ de etanol como solvente dispersor, $250 \mu \mathrm{L}$ de diclorometano como solvente extrator e cerca de $10 \mathrm{mg}$ de cloreto de sódio. A mistura foi levada ao vórtex, agitada por 1 min e posteriormente centrifugada por 2 min a $4000 \mathrm{rpm}$. Por fim, com o auxílio de uma microseringa, transferiu-se a fase orgânica para um microvial que foi levado à análise cromatográfica (Caldas et al., 2011).

\subsection{Análise cromatográfica}

As análises foram realizadas em um Cromatógrafo Gasoso acoplado a um Espectrômetro de Massas (Marca: Agilent Technologie/Modelo: 7890A) composto por uma coluna capilar de sílica fundida (HP-5), com fluxo de gás hélio (gás de arraste) igual a $1,3 \mathrm{~mL} / \mathrm{min}$, split $1: 25$, temperatura do injetor igual a $250^{\circ} \mathrm{C}$, aquecimento com temperatura programada de $60^{\circ} \mathrm{C}$ por 1 minuto, $5^{\circ} \mathrm{C} / \mathrm{min}$ até $100^{\circ} \mathrm{C}, 4^{\circ} \mathrm{C} / \mathrm{min}$ até $150^{\circ} \mathrm{C}$, temperatura mantida por 2 min (Oliveira et al., 2020a; Oliveira et al., 2020b).

Os cromatogramas foram analisados de acordo com seus perfis cromatográficos para a identificação e obtenção da área absoluta dos picos dos metabólitos voláteis presentes nos extratos. O processo de identificação foi realizado com base por meio dos índices de Kovats, segundo o qual uma mistura de hidrocarbonetos alifáticos não ramificados C6 até C15 foi utilizada como mistura padrão. Para tanto, os índices de Kovats calculados foram comparados com os valores da literatura 
(Adams, 2017). Paralelamente, os espectros de massas obtidos foram comparados com os disponíveis no equipamento (biblioteca NIST; similaridade mínima $\geq 60 \%$ ).

\section{Resultados e Discussão}

\subsection{Perfil cromatográfico dos extratos}

Os compostos orgânicos identificados nos extratos foram os monoterpenos nerol, neral, geraniol e geranial. Também foi verificada a presença de dois epóxidos: óxido de epóxi-linalol e um epóxido não identificado. As fórmulas estruturais dos referidos compostos, bem como os dados de índice de Kovats estão evidenciados na Tabela 1.

Tabela 1 - Substâncias identificadas nos extratos, e com seus respectivos tempos de retenção, índice de Kovats teóricos e calculados e similaridade com a biblioteca do espectrômetro de massas.

\begin{tabular}{|c|c|c|c|c|c|}
\hline Nome & Estrutura $^{a}$ & TR (min) & KT & KC & $\operatorname{EK}(\%)$ \\
\hline Nerol & & 13.087 & 1229 & 1228 & 0.05 \\
\hline Neral & & 13.480 & 1238 & 1240 & 0.18 \\
\hline Geraniol & & 13.931 & 1252 & 1252 & 0.08 \\
\hline Geranial & & 14.444 & 1267 & 1267 & 0.05 \\
\hline $\begin{array}{l}\text { Epóxido não } \\
\text { Identificado }^{\text {bentid }}\end{array}$ & & 14.734 & --- & 1275 & --- \\
\hline $\begin{array}{l}\text { Óxido de epoxi- } \\
\text { linalol }^{\mathrm{c}}\end{array}$ & & 14.927 & --- & 1281 & --- \\
\hline
\end{tabular}

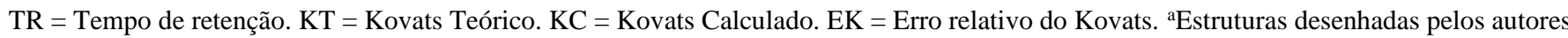
utilizando o programa ChemStetch, 1994. ${ }^{b}$ Não identificado pelo espectro de massas nem pelo índice de Kovats. 'Identificado apenas pelo espectro de massas. Fonte: Dados da pesquisa (2021).

O nerol, neral, geraniol e o geranial apresentaram erros relativos ao índice de Kovats calculado (KC) com o índice de Kovats tabelado (KT) menores que $1,00 \%$, sendo, portanto, índices correspondentes. Por sua vez, a substância de tempo de retenção igual a 14,734 minutos, não apresentou equivalência do espectro de massas com os disponíveis na biblioteca NIST, além de não ser identificada por meio do índice de Kovats. Com base em seu perfil de fragmentação no espectro de massas, foi possível identificá-la como um composto orgânico epoxidado. Os espectros de massas do primeiro epóxido não identificado e do epoxi-linalol apresentaram fragmentações características de epóxidos exibindo picos em m/z de 109, 81, 59, 55 e 43 (Nicolle et al., 2015).

Ao verificar as fragmentações apresentadas nos espectros de massas do nerol, neral, geraniol e do geranial, percebeuse considerável semelhança reforçando a similaridade estrutural, uma vez que todos são monoterpenos acíclicos alcoólicos ou aldeídicos. Os íons m/z 69 e m/z 84 (m/z 83 para os aldeídos) são resultados de uma clivagem bialílica da cadeia desses compostos. Em particular, o íon m/z 69 sofre uma eliminação e perda de uma molécula de eteno, formando o íon m/z 41 
(Rodrigues e Almeida, 2018). Os monoterpenos estão sujeitos a processos de isomerização, provocado pelo aumento da conjugação das ligações covalentes. Em seguida, é possível ocorrer uma clivagem alílica formando íons m/z 69 e m/z 109 (Silverstein et al., 2005). Com relação aos extratos, aqueles obtidos por meio de infusão, com e sem uso de sonicação, em sua maioria não apresentaram os compostos epoxidados. Este resultado indica, possivelmente, que os compostos epoxidados não são representativos no metabolismo secundário do capim limão. Por sua vez, estão presentes nos extratos obtidos a partir da decocção, com ou sem sonicação. A partir deste resultado, infere-se que a formação dos compostos epoxidados esteja mais relacionada ao aumento do tempo de contato entre solvente aquecido e material vegetal, mediante fornecimento de energia na forma de calor. Visto que o linalol é um monoterpeno comum no capim limão e sua similaridade estrutural com o composto orgânico epoxidado, estima-se que o linalol foi oxidado nas posições dos carbonos olefínicos dando origem aos anéis epóxido (Meesters et al., 2007).

\subsection{Análise do primeiro planejamento experimental}

Tendo como base a matriz de ensaios (Tabela 2) e as áreas absolutas dos picos nos cromatogramas (Tabela 3), verifica-se que as folhas resfriadas não apresentaram nerol em seus extratos.

Tabela 2 - Matriz de ensaios para o primeiro planejamento experimental.

\begin{tabular}{cccc}
\hline Ensaio & Método de extração & Tipo de folhas & Período de extração (min) \\
\hline 1 & In/US & Fresca & 5 \\
2 & In & Fresca & 5 \\
3 & In/US & Resfriada & 5 \\
4 & In & Resfriada & 5 \\
5 & In/US & Fresca & 25 \\
6 & In & Fresca & 25 \\
7 & In/US & Resfriada & 25 \\
8 & In & Resfriada & 25 \\
9 & In/US & Fresca & 5 \\
10 & In & Fresca & 5 \\
11 & In/US & Resfriada & 5 \\
12 & In & Resfriada & 5 \\
13 & In/US & Fresca & 25 \\
14 & In & Fresca & 25 \\
15 & In/US & Resfriada & 25 \\
16 & In & Resfriada & 25 \\
\hline
\end{tabular}

Sendo: In = método de extração por infusão, sem sonicação. In/US: método de extração por infusão, com sonicação. Fonte: Dados da pesquisa (2021). 
Tabela 3 - Áreas absolutas dos picos relacionados aos ensaios do primeiro planejamento experimental.

\begin{tabular}{|c|c|c|c|c|c|c|}
\hline Ensaio & Nerol & Neral & Geraniol & Geranial & $\begin{array}{l}\text { Epóxido não } \\
\text { identificado }\end{array}$ & $\begin{array}{c}\text { Óxido de } \\
\text { epoxi-linalol }\end{array}$ \\
\hline 1 & 716894 & 1201500 & 3623459 & 1735171 & --- & --- \\
\hline 2 & 224761 & 2024913 & 1282715 & 4263783 & --- & --- \\
\hline 3 & --- & 172396 & 211420 & 282916 & --- & --- \\
\hline 4 & --- & 847438 & 352912 & 1513559 & --- & --- \\
\hline 5 & 681805 & 5318526 & 3325583 & 9789237 & --- & --- \\
\hline 6 & 1326979 & 3434550 & 6245262 & 4317817 & 531842 & 776005 \\
\hline 7 & --- & 2140666 & 715024 & 4053710 & --- & --- \\
\hline 8 & --- & 1804857 & 508919 & 3288258 & --- & --- \\
\hline 9 & 236081 & 377442 & 1046010 & 548481 & --- & --- \\
\hline 10 & 1358275 & 2299656 & 5923193 & 3306411 & --- & --- \\
\hline 11 & --- & 142347 & --- & --- & --- & --- \\
\hline 12 & --- & 849259 & 428554 & 1735057 & --- & --- \\
\hline 13 & 187748 & 532322 & 911088 & 735055 & --- & --- \\
\hline 14 & 718538 & 1367423 & 3188255 & 1824982 & 305275 & 321514 \\
\hline 15 & --- & 1285515 & 395234 & 2714327 & --- & --- \\
\hline 16 & --- & 1883523 & 690058 & 3457786 & --- & --- \\
\hline
\end{tabular}

Fonte: Dados da pesquisa (2021).

Nos cromatogramas, observou-se que as áreas dos picos correspondentes aos metabólitos são menores para os extratos provenientes de folhas resfriadas quando comparadas com as amostras proveniente de folhas frescas, indicando que a extração foi mais eficiente para as folhas que não passaram pelo armazenamento a frio. Deste modo, afirma-se que chás preparados por infusão de folhas de capim-limão refrigeradas por sete dias podem não apresentar a mesma eficiência farmacológica do que chás preparados com folhas frescas. Tal resultado pode ser compreendido se considerar que no refrigerador, a temperatura não foi suficientemente baixa para prevenir a volatilização dos compostos, e/ou reações de degradação dos metabólitos pelas enzimas presentes nas folhas.

Os compostos epoxidados, por sua vez, foram formados apenas nos extratos obtidos com o método de infusão, sem sonicação, a partir de folhas frescas com período de extração de 25 min. Tal comportamento pode estar relacionado a maior oferta de substrato nas folhas frescas e ao maior período disponível para o processo oxidativo.

Feita a análise descritiva dos resultados, em seguida realizou-se o tratamento dos dados do planejamento experimental. Entre os componentes dos extratos, observou-se um padrão de comportamento para os monoterpenos alcoólicos nerol e geraniol onde apenas o efeito principal do tipo de folhas foi significativo $(\alpha=0,05)$ (Figura 1$)$, sendo o valor do efeito 3461816, t-value -3,44 e o p-value 0,009. Portanto, as áreas dos picos dos monoterpenos alcoólicos aumentam significativamente se usadas folhas frescas ao invés de folhas resfriadas. 
Figura 1 - Análise dos efeitos padronizados dos dados do primeiro planejamento experimental.

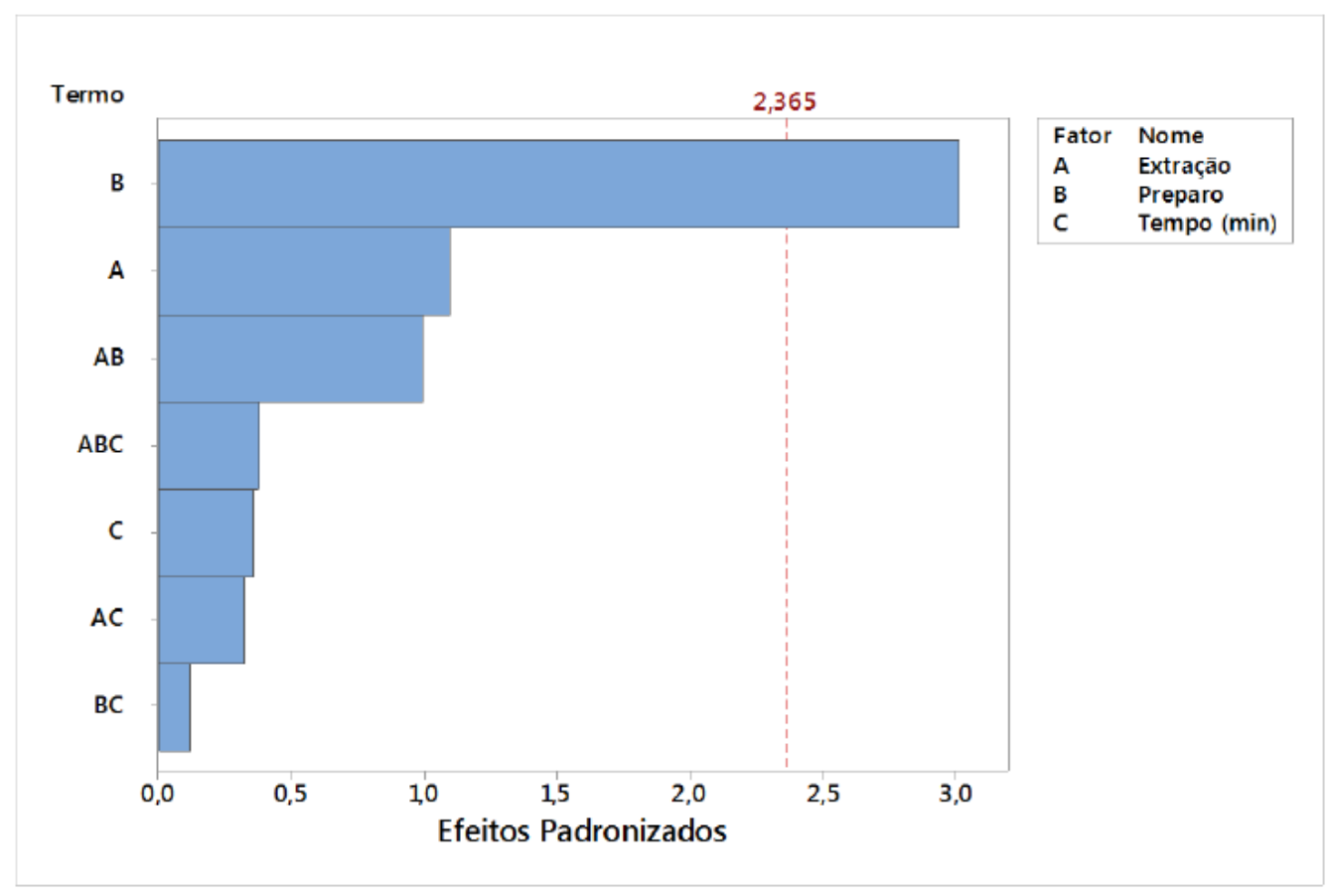

Fonte: Software: Minitab® 19.2020.1 (64-bit).

\subsection{Análise do segundo planejamento experimental}

Considerando como base a matriz de ensaios (Tabela 4) e as áreas absolutas dos picos nos cromatogramas (Tabela 5), verificou-se a ausência do nerol na maioria dos extratos, principalmente aqueles provenientes de folhas secas e obtidos por decocção. A ausência desse monoterpeno em todos os extratos de folha seca pode indicar sua volatilização ou degradação durante o processo de secagem. E a inexistência do nerol nos extratos de folha fresca obtidos via decocção também pode indicar volatilização ou degradação, já que a decocção é uma técnica mais severa.

Em relação aos compostos da classe dos epóxidos, estes foram detectados na maioria dos extratos preparados a partir das folhas secas, mostrando que, possivelmente, o processo de secagem estimula a formação dos compostos oxidados ou cria condições possíveis para extração desses compostos, como remoção da água ou degradação de algum tecido da matriz vegetal. Os epóxidos também são observados nos extratos decorrentes de decocção de folhas frescas. Logo, essa técnica de extração aparenta ser severa o suficiente para que a extração de determinadas substâncias possibilite sua oxidação gerando os derivados epóxidos.

Em seguida, realizou-se o tratamento dos dados do planejamento experimental. Como ocorrido no primeiro planejamento experimental, entre os componentes dos extratos, observou-se um padrão de comportamento para a soma das áreas dos monoterpenos, neste caso, dos compostos epoxidados, onde os efeitos principais do método de extração e do período de extração foram significativos $(\alpha=0,05)$, bem como o efeito de interação entre ambos (Figura 2). $O$ fator método de extração apresentou efeito igual a 10300034, $t$-value 4,42 e $p$-value 0,002 . O fator período de extração teve efeito igual a $7287524, t$ value 3,13 e p-value 0,014. Por fim, o efeito de interação teve efeito igual a 6309294, $t$-value 2,71 e $p$-value 0,027. Dessa forma, afirma-se que as áreas dos picos dos monoterpenos epoxidados aumentam significativamente se o método de xtração por decocção não estiver associado ao processo de sonicação e se o período de extração for maior (25 min). 
Tabela 4 - Matriz de ensaios para o segundo planejamento experimental.

\begin{tabular}{cccc}
\hline Ensaio & Método de extração & Tipo de folhas & Período de extração (min) \\
\hline 1 & In/US & Fresca & 5 \\
2 & Dc & Fresca & 5 \\
3 & In/US & Seca & 5 \\
4 & Dc & Seca & 5 \\
5 & In/US & Fresca & 25 \\
6 & Dc & Fresca & 25 \\
7 & In/US & Seca & 25 \\
8 & Dc & Seca & 25 \\
9 & In/US & Fresca & 5 \\
10 & Dc & Fresca & 5 \\
11 & In/US & Seca & 5 \\
12 & Dc & Seca & 5 \\
13 & In/US & Fresca & 25 \\
14 & Dc & Fresca & 25 \\
15 & In/US & Seca & 25 \\
16 & Dc & Seca & 25 \\
\hline
\end{tabular}

Sendo: Dc = método de extração por decocção, sem sonicação. In/US: método de extração por infusão, com sonicação. Fonte: Dados da pesquisa (2021).

Tabela 5 - Áreas absolutas dos picos relacionados aos ensaios do segundo planejamento experimental.

\begin{tabular}{|c|c|c|c|c|c|c|}
\hline Ensaio & Nerol & Neral & Geraniol & Geranial & $\begin{array}{c}\text { Epóxido não } \\
\text { identificado }\end{array}$ & $\begin{array}{c}\text { Óxido de } \\
\text { epoxi-linalol }\end{array}$ \\
\hline 1 & 716894 & 1201500 & 3623459 & 1735171 & --- & --- \\
\hline 2 & --- & 9878017 & 1512971 & 13410881 & 2214962 & 2603393 \\
\hline 3 & --- & 2817211 & --- & 4326021 & 407054 & 491897 \\
\hline 4 & --- & 879399 & 45437 & 1131910 & 273933 & 293280 \\
\hline 5 & 681805 & 5318526 & 3325583 & 9789237 & --- & --- \\
\hline 6 & --- & 2565213 & 401612 & 3644353 & 4071405 & 4215813 \\
\hline 7 & --- & 6700743 & 497904 & 9623062 & 1016922 & 1335721 \\
\hline 8 & --- & 6156662 & 564892 & 8571999 & 9562711 & 10316180 \\
\hline 9 & 236081 & 377442 & 1046010 & 548481 & --- & --- \\
\hline 10 & --- & --- & 1465934 & 11209722 & 2634264 & 3575404 \\
\hline 11 & --- & 1800639 & --- & 2968377 & 313282 & 294640 \\
\hline 12 & --- & 9392720 & 660974 & 13515842 & 2456484 & 3418113 \\
\hline 13 & 187748 & 532322 & 911088 & 735055 & --- & --- \\
\hline 14 & --- & 875880 & --- & 1456284 & 12608151 & 13336851 \\
\hline 15 & --- & 8463732 & 601829 & 11868500 & 1346986 & 1720166 \\
\hline 16 & --- & 18033194 & 1642572 & 22363858 & 7982394 & 9763600 \\
\hline
\end{tabular}

Fonte: Dados da pesquisa (2021). 
Figura 2 - Análise dos efeitos padronizados dos dados do segundo planejamento experimental.

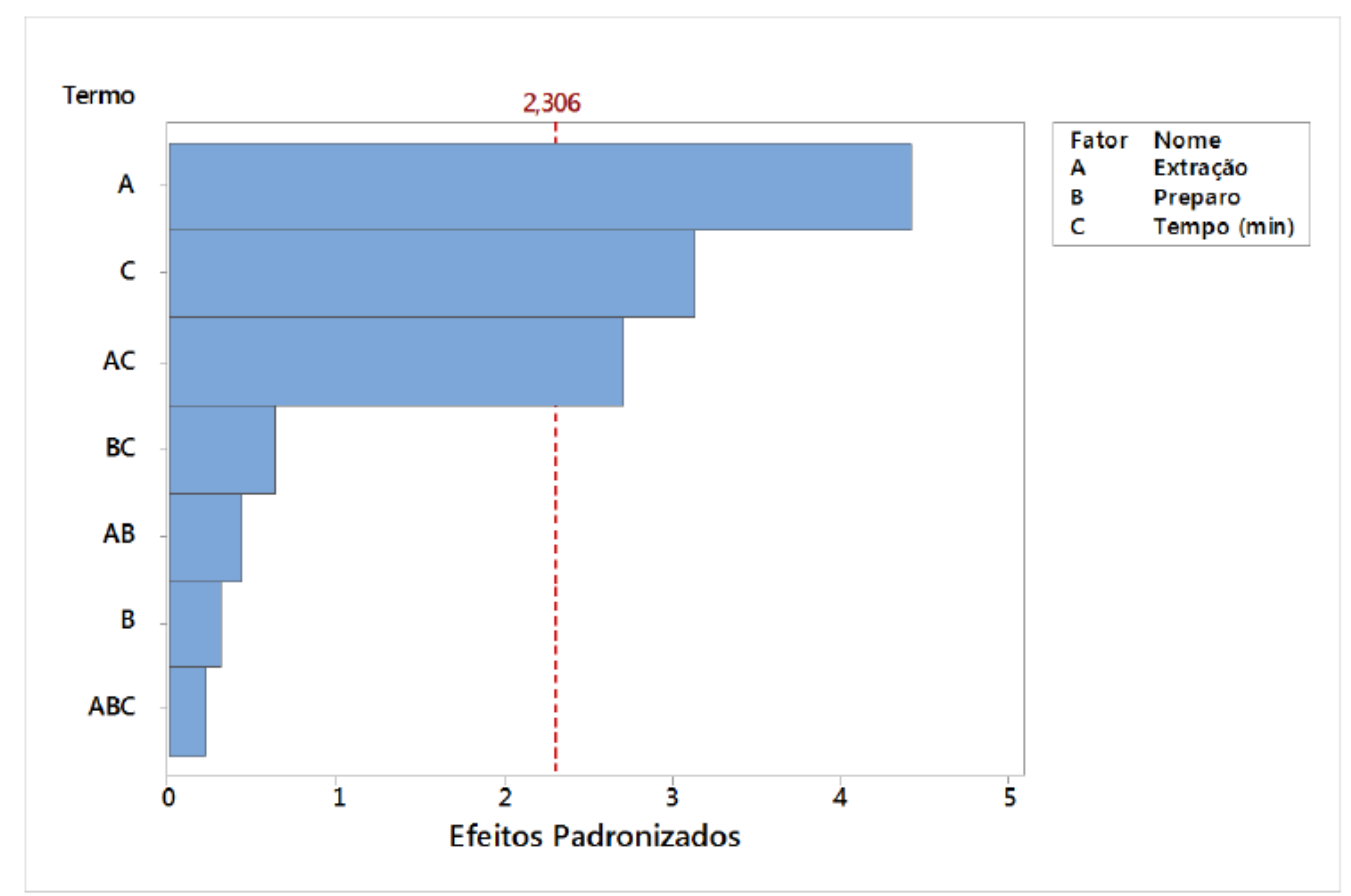

Fonte: Software: Minitab® 19.2020.1 (64-bit).

\subsection{Modelo de regressão}

Buscou-se avaliar se o tempo de extração dos compostos voláteis do capim-limão, relacionado às áreas absolutas, poderiam ser ajustados por meio de modelos de regressão. Isso, pois no estudo dos monoterpenos alcoólicos o período de extração, até 25 min, não foi significativo, ao contrário dos monoterpenos epoxidados, cujo período foi significativo. Assim, considerando a importância dos compostos voláteis bioativos do capim-limão, objetivou-se avaliar o menor período de extração máxima.

Tendo em vista a grande disponibilidade das folhas secas para o consumidor, selecionou-se esta matriz. Por sua vez, a técnica de extração utilizada foi a infusão com sonicação, pois foi responsável pela extração majoritária dos monoterpenos alcoólicos e aldeídicos em detrimento dos monoterpenos peroxidados. Os resultados dos processos de extração e análise dos compostos voláteis estão evidenciados na Tabela 6 .

Ao avaliar os resultados, observou-se que o nerol não foi identificado em nenhum dos extratos, possivelmente por este metabólito ter volatilizado ou degradado durante o processo de secagem. Do mesmo modo, o geraniol não foi detectado nos extratos cuja infusão foi promovida em $5 \mathrm{~min}$. Estima-se que o processo de secagem tenha sido responsável por dificultar a extração do metabólito no curto período. Em períodos mais longos, o contato entre a matriz vegetal e o solvente, em meio à sonicação, foi eficaz.

Ao longo do período de extração, observou-se o aumento das áreas dos picos dos monoterpenos não epoxidados, indicando uma maior eficiência de extração para 65 min. Paralelamente, ao considerar os monoterpenos epoxidados, observase que há um aumento da extração entre 5 e 25 min, uma variação moderada entre 25 e 45 min e um aumento abrupto em 65 min. Uma hipótese para este comportamento pode ser a extração dos monoterpenos epoxidados, provenientes da secagem, cujo valor máximo foi identificado entre 25 e 45 min. O posterior aumento de sua concentração, possivelmente se deve à novas reações de oxidação relacionadas à sua síntese ao longo da extração, após 45 min. 
Tabela 6 - Áreas absolutas dos picos dos compostos voláteis de capim cidreira relacionados ao estudo de regressão.

\begin{tabular}{cccccc}
\hline Tempo (min) & Neral & Geraniol & Geranial & Epóxido não identificado & Óxido de epoxi-linalol \\
\hline 5 & 2817211 & - & 4326021 & 407054 & 491897 \\
5 & 1800639 & - & 2968377 & 313282 & 294640 \\
25 & 6700743 & 497904 & 9623062 & 1016922 & 1335721 \\
25 & 8463732 & 601829 & 11868500 & 1346986 & 1720166 \\
35 & 10902819 & 1253772 & 19150209 & 1042773 & 1532715 \\
35 & 12423025 & 1232436 & 22486918 & 1007433 & 1326232 \\
45 & 16092557 & 1574660 & 27043066 & 1226846 & 1797581 \\
45 & 15181215 & 1522217 & 27581427 & 1019929 & 1472038 \\
65 & 28535523 & 3635468 & 45134478 & 2884991 & 3983794 \\
65 & 31923379 & 3545312 & 54698795 & 2551871 & 3904743 \\
\hline
\end{tabular}

Fonte: Dados da pesquisa (2021).

Ao considerar a soma das áreas dos monoterpenos aldeídicos, obteve-se uma regressão quadrática (área $=4180621$ $+263008 *$ tempo $+13899 *$ tempo $\left.^{2}\right)$ de boa qualidade $\left(\mathrm{R}^{2}=0,9816\right)$. Somado a isso, o modelo foi adequado, pois o teste ANOVA apresentou estatística F elevada, igual a 186,67, com valor p =0,000, bem como a análise de variância sequencial (F = 18,84; valor $\mathrm{p}=0,003$ ). Ao final, os resíduos se apresentaram de forma aleatória, com distribuição normal, independentes e homocedásticos, sendo apenas a variabilidade dos pontos em 65 min um pouco mais destacada (Figura 3a). Por sua vez, a soma das áreas do geraniol foi modelada com uma regressão quadrática (área $=-16820+3144 *$ tempo $+795,8 *$ tempo ${ }^{2}$ ) de ótima qualidade $\left(\mathrm{R}^{2}=0,9902\right)$. O modelo foi adequado, (ANOVA: F 355,19, valor p 0,000; variância sequencial: F 18,84, valor p 0,003), com resíduos aleatórios, distribuídos normalmente, sendo independentes e homocedásticos (Figura 3b). Também foi possível aplicar a regressão quadrática à soma das áreas dos monoterpenos aldeídicos com o geraniol: área = $4163801+266151 *$ tempo + 14695*tempo ${ }^{2}, \mathrm{R}^{2}=0,9830$; ANOVA: F 202,16, valor p 0,000; variância sequencial: F 20,75, valor p 0,003), com resíduos aleatórios, distribuídos normalmente, sendo independentes e homocedásticos (Figura 3c).

Ao considerar os monoterpenos epoxidados, os modelos de regressão testados não apresentaram todas as características de qualidade e ajuste atendidas, resultado possivelmente associado às peculiaridades do aumento das áreas ao longo de período de extração.

De modo geral, o êxito na obtenção dos modelos para os monoterpenos não epoxidados permite a previsão de obtenção dos monoterpenos ao longo do período de estudo, dentro do contexto de análises quantitativas. A referida previsão tem potencial de uso associada a estudos de aplicação fitoquímica dessas substâncias, bem como da matriz vegetal. 
Figura 3 - Modelos de regressão aplicados à das áreas absolutas dos picos dos monoterpenos aldeídicos, geraniol e da soma da ambos com relação ao tempo. Sendo: $\mathrm{a}=$ monoterpenos aldeídicos, $\mathrm{b}=$ geraniol e $\mathrm{c}=$ soma dos monoterpenos aldeídicos com o geraniol.

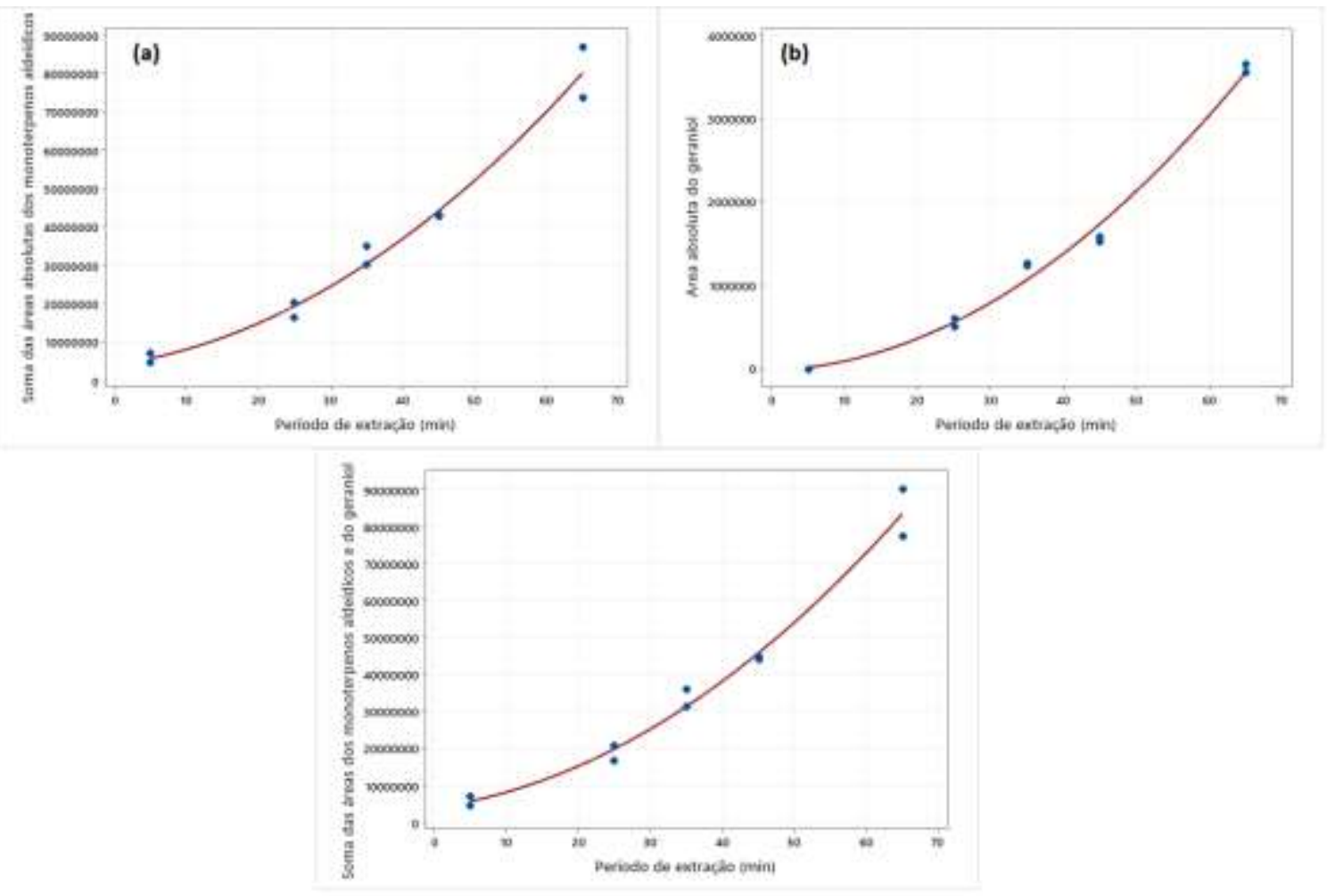

Fonte: Software: Minitab® 19.2020.1 (64-bit).

\section{Conclusão}

O preparo dos extratos aquosos de capim limão, utilizando folhas frescas, refrigeradas e secas e, empregando variações nas metodologias de decocção e maceração, após microgeração, levou a identificação da presença dos monoterpenos acíclicos alcoólicos (nerol e geraniol), aldeídicos (neral e geranial) e epoxidados (óxido de epoxi-linanol e outro não identificado).

O uso de folhas resfriadas reduz a obtenção dos monoterpenos alcoólicos e aldeídicos, que são identificados na literatura como bioativos. O uso de folhas frescas e secas, conduz a extratos de perfis químicos semelhantes. Em relação aos processos de extração, foi observado que o aumento do período de aquecimento durante a decocção resulta no acúmulo de monoterpenos epoxidados, que são espécies indesejadas em fitoterápicos. Tal acúmulo pode ser decorrente de uma maior extração ou da conversão química dos monoterpenos nestas espécies oxidadas, mediante a ação do calor. Portanto, para obtenção de extratos livres, deste tipo de metabólito, a infusão seria o processo de extração mais indicado.

Do ponto de vista estatístico é possível destacar que a obtenção do geraniol e dos monoterpenos aldeídicos pode ser modelada via regressão quadrática, sendo tal comportamento fundamental na previsão dos teores dentro do período estudado e em paralelo com as aplicações do fitoterápico em diferentes condições de extração.

\section{Referências}

Adams, R. P. (2017). Identification of essential oil components by gas chromatography/mass spectrometry. (4a ed.) Allured Publishing Corporation. 
Allahverdiyev, A., Duran, N., Ozguven, M. \& Koltas, S. (2004). Antiviral activity of the volatile oils of Melissa officinalis L. against Herpes simplex virus type-2. Phytomedicine, 11, 657-661.10.1016/j.phymed.2003.07.014.

ANVISA, Agência Nacional de Vigilância Sanitária. (2018) Primeiro Suplemento do Formulário de Fitoterápicos da Farmacopeia Brasileira.

Bachiega, T. F. \& Sforcin, J. M. (2011). Lemongrass and citral effect on cytokines production by murine macrophages. Journal Ethnopharmacology, 137 (1), 909-913. 10.1016/j.jep.2011.07.021.

Burke, Y. D., Stark, M. J., Roach, S. L., Sen, S. E. \& Crowell, P. L. (1997). Inhibition of pancreatic cancer growth by the dietary isoprenoids farnesol and geraniol. Lipids, 32 (2), 151-156. 10.1007/s11745-997-0019-y.

Caldas, S. S., Gonçalves, F. F., Primel, E. G., Prestes, O. D., Martins, M. L. \& Zanella, R. (2011). Principais técnicas de preparo de amostras para determinação de resíduos de agrotóxicos em água por cromatografia líquida com detecção por arranjo de diodos e por espectrometria de massas. Química nova, 34 (9), 1604-1617. 10.1590/S0100-4042201100090002.

Cantrell, C. L., Franzblau, S. G. \& Fischer, N. H. (2009). Antimycobacterial Tiwari, M. and P. Kakkar, Plant derived antioxidants-geraniol and camphene protect rat alveolar macrophages against t-BHP induced oxidative stress. Toxicology in vitro, 23 (2), 295-301.10.1016/j.tiv.2008.12.014.

Costa, L. C. B., Corrêa, R. M., Cardoso, J. C. W., Pinto, J. E. B. P., Bertolucci, S. K. V. \& Ferri, P. H. (2005). Secagem e fragmentação da matéria seca no rendimento e composição do óleo essencial de capim-limão. Horticultura brasileira, 23 (4), 956-959.10.1590/S0102-05362005000400019.

Chen, W. \& Viljoen, A. M. (2010). Geraniol - A review of a commercially important fragrance material. South African Journal of Botany, 76, 643-651. 10.1016/j.sajb.2010.05.008.

Cunico, M. W. M., Cunico, M. M., Miguel, O. G., Zawadzki, S. F., Peralta-Zamora, P. \& Volpato, N. (2008). Planejamento fatorial: uma ferramenta estatística valiosa para a definição de parâmetros experimentais empregados na pesquisa científica. Visão Acadêmica, 9 (1), 23-33. 10.5380/acd.v9i1.14635.

Escobar, P., Leal, S. M., Herrera, L. V., Martinez, J. R. \& Stashenko, E. (2010). Chemical composition and antiprotozoal activities of Colombian Lippia spp essential oils and their major components. Membro do Instituto Oswaldo Cruz, 105, 184-190. 10.1590/S0074-02762010000200013.

Falleh, H., Ksouri, R., Lucchessi, M. E., Abdelly, C. \& Magné, C. (2012). Ultrasound-Assisted Extraction: Effect of Extraction Time and Solvent Power on the Levels of Polyphenols and Antioxidant Activity of Mesembryanthemum edule L. Aizoaceae Shoots. Tropical Journal of Pharmaceutical Research, 11 (2), 243-249. 10.4314/tjpr.v11i2.1.

Firmo, W. C. A, Menezes, V. J. M., Passos, C. E. C., Dias, C.N., Alves, L. P. L., Dias, I. C. L., Neto, M. S. \& Olea, R. S. G. (2011). Contexto histórico, uso popular e concepção científica sobre plantas medicinais. Caderno de Pesquisa, 18 (especial).

Friedman, M., Henika, P. R. \& Mandrell, R. E. (2002). Bactericidal activities of plant essential oils and some of their isolated constituents against Campylobacter jejuni, Escherichia coli, Listeria monocytogenes, and Salmonella enterica. Journal of food protection, 65 (10), 1545-1560. 10.4315/0362$028 X-65.10 .1545$

Giteru, S. G., Coorey, R., Bertolatti, D., Watkin, E., Johnson, S. \& Fang, Z. (2015). Physicochemical and antimicrobial properties of citral and quercetin incorporated kafirin-based bioactive films. Food Chemitry, 168, 341-347. 10.1016/j.foodchem.2014.07.077.

Gnoatto, S. C. B., Bassani, V. L., Coelho, G. C. \& Schenkel, E. P. (2007). Influence of the extraction methodology on the methylxanthines content of maté (Ilex paraguariensis a. St.-Hil., aquifoliaceae). Química Nova, 30 (2), 304-307. 10.1590/S0100-40422007000200012.

Guimarães, L. G. de L., Cardoso, M. das G., Zacaroni, L. M. \& Lima, R. K. (2008). Influência da luz e da temperatura sobre a oxidação de óleo essencial de capim-limão (Cymbopogon citratus stapf). Química nova, 31 (6), 1476-1480. 10.1590/S0100-40422008000600037.

Gurgel do Vale, T., Furtado, E. C., Santos Jr., J. G. \& Viana, G. S. B. (2002). Central effects of citral, myrcene and limonene, constituents of essential oil chemotypes from Lippia alba (Mill.) N.E. Brown. Phytomedicine, 9 (8), 709-714. 10.1078/094471102321621304.

Herman, A., Tambor, K. \& Herman, A. (2016). Linalool Affects the Antimicrobial Efficacy of Essential Oils. Current Microbiology, 72 (2). Doi: 165$172,10.1007 / \mathrm{s} 00284-015-0933-4$.

Jeon, J., Lee, C. \& Lee, H. (2009). Food protective effect of geraniol and its congeners against stored food mites. Journal of food protection, 72 (7), 1468 1471. $10.4315 / 0362-028 X-72.7 .1468$

Li, X. J., Yang, Y. J., Li, Y. S., Zhang, W. K. \& Tang, H. B. (2016). $\alpha$-Pinene, Linalool, and 1-Octanol Contribute to the Topical Anti-inflammatory and Analgesic Activities of Frankincense by Inhibiting COX-2. Journal of Ethnopharmacology, 179, 22-26. 10.1016/j.jep.2015.12.039.

Maeda, H., Yamazaki, M. \& Katagata, Y. (2012). Kuromoji (Lindera umbellata) Essential Oilinduced Apoptosis and Differentiation in Human Leukemia HL60 Cell. Experimental Therapeutic Medicine, 3 (1), 49-52. 10.3892/etm.2011.357.

Maran, J. P., Manikandan, S., Nivetha, C. V. \& Dinesh, R. (2017). Ultrasound assisted extraction of bioactive compounds from Nephelium lappaceum L. fruit peel using central composite face centered response surface design. Arabian Journal of Chemistry, 10 (1), S1145-S1157. 10.1016/j.arabjc.2013.02.007.

Marques, T. H. C., Marques, M. L. B. G. C. B., Lima, D. dos S., Siqueira, H. D. S., Neto, J. D. N., Branco, M. do S. B. G. C., Souza, A. A., Sousa, D. P. \& Freitas, R. M. (2013). Evaluation of the neuropharmacological properties of nerol in mice. World Journal of Neurology, 3 (1). 10.4236/wjns.2013.31004.

Martinazzo, A. P., Corrêa, P. C., Resende, O. \& Melo, E. de C. (2007). Análise e descrição matemática da cinética de secagem de folhas de capim-limão. Revista brasileira de engenharia agrícola e meio ambiente, 11 (3), 301-306. 10.1590/S1415-43662007000300009.

Meesters, R. J. W., Duisken, M. \& Hollender, J. (2007). Study on the cytochrome P450-mediated oxidative metabolism of the terpene alcohol linalool: Indication of biological epoxidation. Journal of Xenobiotics, 37 (6), 604-617. 10.3109/00498250701393191. 
Negrelle, R. R. B. \& Gomes, E. C. (2007). Cymbopogon citratus (DC.) Stapf: chemical composition and biological activities. Revista Brasileira de Plantas Medicinais, 9 (1), 80-92.

Nicolli, K. P., Welke, J. E., Closs, M., Caramão, E. B., Costa, G., Manfroi, V. \& Zini, C. A. (2015). Characterization of the volatile profile of Brazilian Moscatel Sparkling wines through solid phase microextraction and gas chromatography. Journal of Brazilian Chemistry Society, 0, 1-20. 10.5935/01035053.20150110.

Nishiyama, M. F., Costa, M. A. F., Costa, A. M., Souza, C. G. M., Boer, C. G., Bracht, C. K. \& Peralta, R. M. (2010). Brazilian green tea (Camellia sinensis var assamica): effect of infusion time, mode of packaging and preparation on the extraction efficiency of bioactive compounds and on the stability of the beverage. Ciência e Tecnologia dos Alimentos, 30 (1), 191-196. 10.1590/S0101-20612010000500029

Oliveira, J. B. de, Machado, A. M. de R., Nelson, D. L. \& Lucas, E. M. F. (2020a). Extraction of bioactive metabolites from sucupira seeds (Pterodon emarginatus) using cachaça. RSD [Internet], 9 (11), e2109119795. 10.33448/rsd-v9i11.9795.

Oliveira, J. B. de, Silva, B. F. L. da, Machado, A. M. de R., Lucas, E. M. F. (2020b). Influence of the storage conditions of sucupira's seeds alcoolatures (Pterodon emarginatus) in the presence of their bioactive metabolites. RSD [Internet], 9 (11), e3509119833. 10.33448/rsd-v9i11.9833.

Oyedele, A. O., Gbolade, A. A., Sosan, M. B., Adewoyin, F. B., Soyelu, O. L. \& Orafidiya, O. O. (2002). Formulation of an effective mosquito-repellent topical product from lemongrass oil. Phytomedicine, 9 (3), 259-262. 10.1078/0944-7113-00120.

Rao, V. S. N., Menezes, A. M. S. \& Viana, G. S. B. (1990). Effect of myrcene on nociception in mice. Journal of Pharmacy and Pharmacology, 42, 877-878. 10.1111/j.2042-7158.1990.tb07046.x.

Robbers, J. E., Speedie, M. K. \& Tyler, V. E. (1996). Pharmacognosy and pharmacobiotechnology. Williams \& Wilkins.

Rodrigues, A. B. L. \& Almeida, S. S. M. S. (2018). Identificação do mirceno em óleos essenciais por espectroscopia de massas: uma revisão sistemática. Revista de biologia e ciência da terra, 18 (1), 16-24.

Rufino, A. T., Ribeiro, M., Sousa, C., Judas, F., Salgueiro, L., Cavaleiro, C. \& Mendes, A. F. (2015). Evaluation of the anti-inflammatory, anti-catabolic and pro-anabolic effects of E-caryophyllene, myrcene and limonene in a cell model of osteoarthritis. European Journal of Pharmacology, 750 (5), 141-150. 10.1016/j.ejphar.2015.01.018.

Shah, G., Shri, R., Panchal, V., Sharma, N., Singh, B. \& Mann, A. S. M. (2011). Scientific basis for the therapeutic use of Cymbopogon citratus, stapf (Lemon grass). Journal of Advanced Pharmaceutical Technology e Research, 2 (1), 3-8. 10.4103/2231-4040.79796.

Si, W., Gong, J., Zhou, T., Yu, H., Poppe, C., Johnson, R. \& Du, Z. (2006). Antimicrobial activity of essential oils and structurally related synthetic food additives towards selected pathogenic and beneficial gut bacteria. Journal of Applied Microbiology, 100 (2), 296-305. 10.1111/j.1365-2672.2005.02789.x.

Silverstein, R. M., Webster, F. X. \& Kiemle, D. J. (2005). Spectrometric Identification of Organic Compounds. (7a ed.) John Wiley \& Sons.

Simões, C. M. O., Schenkel, E. P., Mello, J. C. P. de, Menenzt, L. A. \& Petrovick, P. R. (2017). Farmacognosia do Produto natural ao Medicamento. Artmed.

Singi, G., Damasceno, D. D., D'andréa, E. D. \& Silva, G. A. (2005). Efeitos agudos dos extratos hidroalcoólicos do alho (Allium sativum L.) e do capim-limão (Cymbopogon citratus (DC) Stapf) sobre a pressão arterial média de ratos anestesiados. Revista brasileira de farmacognosia, 15 (2), 94-97. 10.1590/S0102$695 \times 2005000200004$

Sobral, M. V., Xavier, A. L., Lima, T. C. \& Sousa, D. P. (2014). Antitumor Activity of Monoterpenes Found in Essential Oils. The Scientific World Journal, 1-35. 10.1155/2014/953451.

Stamp N. (2003). Out of the quagmire of plant defense hypotheses. The Quarterly Review of Biology, 78 (1), 23-55. 10.1086/367580.

Topal, U., Sasaki, M., Goto, M. \& Otles, S. (2008). Chemical compositions and antioxidant properties of essential oils from nine species of Turkish plants obtained by supercritical carbon dioxide extraction and steam distillation. Internet Journal of Food Science Nutrition, 59, 619-634. $10.1080 / 09637480701553816$. 